\title{
BERNARDAS LOWNAS: LIETUVIŲ KILMĖS DEFIBRILIATORIAUS IŠRADĖJAS IR NOBELIO TAIKOS PREMIJOS LAUREATAS
}

\author{
Aurelija Martinonytė ${ }^{1}$, Pranas Šerpytis ${ }^{1,2}$, Joseph S. Alpert ${ }^{3}$, Aleksandras Laucevičius ${ }^{1,2}$ \\ ${ }^{1}$ Vilniaus universiteto Medicinos fakultetas, ${ }^{2}$ Vilniaus universiteto ligoninès Santaros kliniku \\ Širdies ir kraujagyslių ligu klinika, ${ }^{3}$ Department of Medicine, University of Arizona
}

Raktažodžiai: Bernardas Lownas, Boruchas Lacas, defibriliatorius, aritmijos, Nobelio taikos premija.

\begin{abstract}
Santrauka
Straipsnyje apžvelgiama žymaus Lietuvos žydų kilmès kardiologo Bernardo Lowno (1921 - 2021) biografija, pažymint svarbiausius jo nuopelnus medicinai ir visuomenei. Iš Utenos kilęs B. Lownas per beveik šimtmeti trukusį savo gyvenimą kardinaliai pakeitè šiuolaikinę kardiologiją: jam priskiriamas modernaus defibriliatoriaus kardioverterio išradimas, reikšmingos aritmijų medikamentinio gydymo ir koronarinès širdies ligos pacientu priežiūros inovacijos. Straipsnyje aptariama Nobelio taikos premija apdovanota B. Lowno ir kolegų iniciatyva „Pasaulio gydytojai prieš branduolinį karą" bei jo darbai, siekiant sveikatos priežiūros pažangos besivystančiose šalyse. Gydytojas B. Lownas prisimenamas kaip iškili asmenybė, savo gyvenimą paskyrusi žmogui ir žmonijai. Ivadas
\end{abstract}

Šimtujų Bernardo Lowno gimimo metinių proga prisimename iškilų lietuvių kilmès kardiologą, mokslininką ir visuomenininką, ženkliai prisidejusị ne tik prie savo pacientų, bet ir milijonų žmonių gerovès visame pasaulyje.

Tikslas - supažindinti Lietuvos medikų bendruomenę su išskirtine Bernardo Lowno asmenybe ir paminèti gydytojo atminimą šimtmečio proga.

\section{B. Lowno biografija}

Gydytojas Bernardas Lownas (Boruchas Lacas) gimè 1921 birželio 7 d. Utenoje, žydų šeimoje. Čia gyveno iki keturiolikos metų, kol $1935 \mathrm{~m}$. su šeima pasitraukè ị JAV [1]. Akademini kelią B. Lownas pradėjo nuo zoologijos studijų Meino universitete, kurias $1942 \mathrm{~m}$. vienintelis iš 700 studentuc baigè ypač gerais rezultatais ir gavo diplomą Summa cum laude. Vèliau studijavo John Hopkins universiteto Medicinos fakultete, kurị baigè 1945 metais [2,3].
Dar būdamas medicinos studentas, B. Lownas išsiskyrè savo pasišventimu žmonèms: prireikus, nusižengdamas tuometinèms taisyklèms, atlikdavo kraujo transfuzijas tarp skirtingų rasių asmenų, buvo studentų organizacijos, siekusios moterų ir žydų prièmimo ị medicinos mokyklas, lyderis [4,5].

Ankstyvieji darbai. Klinikinę praktiką B. Lownas pradejjo Jeilio universitetineje ir Bruklino žydų ligoninèse. 1950 m., dirbdamas Bostono Peterio Brighamo ligoninès kardiologijos skyriuje, tapo Harvardo universiteto mokslininku. Prisijungęs prie Harvardo T.H. Chan visuomenès sveikatos mokyklos mitybos departamento, B. Lownas vienas pirmuju èmé domètis gyvensenos ịtaka vadinamujjų civilizacijos ligų išsivystymui, ypatingą dèmesį skirdamas kardiovaskulinėms ligoms [6].

Bostono Peterio Brighamo ligoninès kardiologijos skyriuje B. Lowno mentoriumi tapo žymus kardiologas Samuelis A. Levinas. Dirbdamas su mentoriumi ir stebedamas aukštus mirštamumo po miokardo infarkto rodiklius, B. Lownas padare išvadą, jog tokius prastus gydymo rezultatus lèmé tuo metu paplitusi griežto lovos režimo ir ilgalaikès hospitalizacijos taktika.

Remiamas S. Levino ir nepaisydamas pradinio gydytojų bendruomenès pasipriešinimo, $1952 \mathrm{~m}$. B. Lownas pasiūlè ankstyvos mobilizacijos po miokardo infarkto taktiką, žinomą kaip ,sėdimoji terapija“ (angl. armchair treatment). Gydytojas argumentavo, jog šis paprastas veiksmas leidžia sumažinti tūrio apkrovą širdžiai, mažina plaučių edemą, apsaugo nuo plaučiu tromboembolijos, gerina paciento psichologinę būklę ir komfortą. Metodo efektyvumą B. Lownas pademonstravo ji pritaikydamas 81 pacientui, kurių mirštamumas, palyginus su iprastai slaugomais ligoniais, sumažejo dviem trečdaliais. Netrukus ankstyvosios mobilizacijos taktiką imta taikyti visuotinai, ženkliai pagerinant pacientų ligos baigtị bei sutrumpinant hospitalizacijos trukmę [7].

Šiuolaikinio defibriliatoriaus išradimas. Neabejotinai žinomiausias B. Lowno išradimas - defibriliatorius kardio- 
verteris - buvo sukurtas gydytojo įžvalgumo ir inovatyvaus mąstymo dèka. Elektros iškrovas širdies veiklos atkūrimui buvo bandoma taikyti jau nuo XX amžiaus pradžios, bet tokio gydymo rezultatai nebūdavo geri. Šeštajame dešimtmetyje amerikiečių kardiologas Paul Zoll pasiūlè defibriliacijai naudoti kintamają elektros srovę, tačiau 1959 metais B. Lownas ịrode, jog šis metodas sukelia didelius skeleto ir širdies raumens pažeidimus ir gali būti potencialiai mirtinas.

Remdamasis savo pastebejjimais ir dirbdamas su kolegomis, $1961 \mathrm{~m}$. B. Lownas pasiūlè širdies ritmo atkūrimui taikyti ne kintamosios, o nuolatinès srovès iškrovas. Kiek vèliau B. Lownas nustatè, jog šis metodas gali būti taikomas ne tik širdies sustojimo atveju, bet ir gydant gyvybei nepavojingas aritmijas, tokias kaip prieširdžių virpejjimas. Jis identifikavo saugų defibriliacijai širdies ciklo laiką, leidžiantị išvengti grèsmingų komplikacijų (skilvelių virpèjimo ar staigios širdinès mirties) ir pavadino tokị sinusinio širdies ritmo atkūrimo metodą kardioversija [8]. Vieno iš širdies chirurgijos pradininkų Donaldo B. Efflerio teigimu, šis defibriliatoriaus kardioverterio išradimas leido vystytis moderniajai kardiochirurgijai: defibriliacija Klivlando klinikos operacinejje pradèta taikyti 1962 metais, o $1967 \mathrm{~m}$. ši technologija ịgalino Rene Favaloro atlikti pirmają dokumentuotą koronarinio šunto suformavimo operaciją $[9,10]$.

Darbai aritmijų srityje. B. Lownas reikšmingai prisidèjo ir prie medikamentinio aritmiju gydymo. Atlikdamas rezidentūrą Niujorko Montefiore ligoninejje, jis domèjosi digitalio preparatu vartojimu. Gydytojas pademonstravo, jog šių vaistų toksinis poveikis gali būti kontroliuojamas stebint ir koreguojant kalio koncentraciją organizme bei pasiūlè ilgo poveikio digitoksiną pakeisti saugesniu trumpo veikimo digoksinu [3]. B. Lownas taip pat atkreipé dèmesị ị kalio netekimo klinikinę reikšmę, skiriant ịvairius diuretikus [11]. Kiek vèliau, 1964 m., B. Lownas aritmiju gydymui pasiūlè lidokainą, kuris iki tol buvo naudotas tik kaip anestetikas odontologijoje [3,12].

Specializuotos priežiūros pradžia. 1965-aisiais B. Lownas Bostono Peterio Brighamo ligoninèje ịkūrè vieną pirmujų specializuotų koronarinès širdies ligos skyrių (angl. Coronary care unit), skirtą ritmo sutrikimų gydymui ir komplikacijų prevencijai. Taikydamas ilgalaikę elektrokardiografiją ir patyrusių slaugytojų priežiūrą, gydytojas pademonstravo ankstyvojo aritmijų nustatymo galimybes bei savalaikio gydymo svarbą, išvengiant grèsmingų komplikacijų [1].

Skilvelinių ekstrasistolių klasifikacija. Ilgus metus domejjęsis aritmijomis ir staigia širdine mirtimi, $1971 \mathrm{~m}$. B. Lownas kartu su kolega Marshall Wolf sudarè plačiai žinomą skilvelinių ekstrasistolių klasifikaciją, paremtą jų dažniu, kilme, išsidèstymu grupèmis ir ankstyvumu. Buvo pastebèta, jog aukštesnei klasei priskiriamos skilvelinès eks- trasistolès yra ypač pavojingos nestabilia krūtinės angina, miokardo infarktu, hipertrofine kardiomiopatija ir kitomis kardiovaskulinès sistemos ligomis sergantiems pacientams, todèl jų identifikavimas leido užtikrinti savalaikę ir atidžią pacientų priežiūrą [13].

Visuomeninė veikla. Neatsiejama B. Lowno biografijos dalis - jo visuomenine veikla. Jausdamas branduolinio karo tarp Jungtinių Amerikos Valstijų ir Sovietų Sajungos grèsmę, 1961 metais B. Lownas èmè telkti vietos kolegas darbui, siekiant branduolinio nusiginklavimo. Kiek vèliau, 1980-aisiais, judejimas peraugo ị tarptautinę sajungą „Pasaulio gydytojai prieš branduolinį karą“ (angl. International Physicians for the Prevention of Nuclear War, IPPNW). Aktyviausiu veikimo periodu organizacija buvo subūrusi virš 200 tūkst. narių iš ìvairių pasaulio regionų. $1985 \mathrm{~m}$. iniciatyva ir jos lyderiai buvo ịvertinti Nobelio taikos premija $[3,14]$.

B. Lowno aktyvumas neapsiribojo branduolinio karo prevencija. Gydytojas prisidejo prie Atsakomybès už Vietnamo kare sužeistus vaikus komiteto (angl. Committee of Responsibility for War Injured Vietnamese Children, COR) veiklos, kuris pasieké, kad Vietnamo kare sužeisti vaikai būtų skraidinami nemokamam gydymui ị JAV [15].

B. Lownas žinomas ir dèl savo darbų, atliktų siekiant sveikatos priežiūros pažangos besivystančiose šalyse. Gydytojas įtikino Sovietų Sajungos vadovus pakeisti balistinès raketos paskirti, ją panaudojant satelito iškélimui į Žemès orbitą. Taip 1988 m. gimé projektas SatelLife, kurio dèka besivystančių šalių medikai minèto satelito pagalba buvo aprūpinami naujausia medicinine literatūra [6]. 1997 metais B. Lownas pritaikè dar tik besikuriantị pasaulinị interneto tinklą edukaciniam projektui ProCor, kurio tikslas buvo gydytojus ir kitus sveikatos darbuotojus visame pasaulyje šviesti apie kardiovaskulines ligas ir jų prevenciją [16].

Rašytinis palikimas. Be gausios mokslinès literatūros, B. Lownas parašè keletą knygų, kuriose dalinosi savo patirtimi ir pasaulèžiūra. 1996 metais išleistame kūrinyje „The Lost Art of Healing“ (Prarastasis gydymo menas) B. Lownas kalba apie ryšio tarp gydytojo bei paciento svarbą, pabrěždamas, jog ịsiklausymas ị pacientą - svarbiausias gydytojo instrumentas, kurio negali pakeisti jokios moderniosios technologijos. Gydytojas akcentuoja, jog ragindamas susitelkti i dèmesingą bendravimą su pacientu anaiptol neskatina atsisakyti šiuolaikinių medicinos laimèjimų, tačiau kviečia juos apjungti, kuriant pažangią sveikatos priežiūrą atsigrịžtant ị žmogų. Panaši tema nagrinèjama ir 2000 metais išleistame veikale „Practicing the Art while mastering the Science“ (Menas ịvaldyti mokslą) [3,17].

2008-aisiais išleistuose memuaruose „Prescription for Survival“ (Išgyvenimo receptas), B. Lownas pasakoja neitikètiną istoriją, kaip Šaltojo karo metais JAV ir Sovietų Sajungos 
gydytojai susivienijo bendram tikslui - kovai prieš branduolini karą, igavusiam Nobelio taikos premija apdovanotos organizacijos „Pasaulio gydytojai prieš branduolinį karą“ pavidalą. Knygoje nagrinėjamos branduolinio ginklavimosi varžybų priežastys bei visuomenès vaidmuo ir svarba, siekiant saugesnio rytojaus [18].

Gydytojo atminimas. B. Lownas kolegų atmintyje išlieka ne tik kaip išskirtinis kardiologas, mokslininkas ir visuomenininkas, bet ir kaip puikus mokytojas. Savo prisiminimais apie gydytoją B. Lowną dalijasi Joseph S. Alpert - amerikiečių kardiologas, Amerikos medicinos žurnalo (angl. American Journal of Medicine) vyriausiasis redaktorius: „Gydytojas B. Lownas buvo vienas geriausių ir ịtakingiausių mokytojų, iš kurių teko garbė mokytis atliekant internatūrą ir rezidentūrą Harvardo universiteto Peterio Brighamo ligonineje 7 dešimtmetyje. Jau būdami rezidentais žinojome apie B. Lowno novatoriškus darbus aritmijų, koronarinių širdies ligų priežiūros ir klinikinès kardiologijos srityse."

J. Alpert pasakoja, jog B. Lownas nuolat skyrè laiko profesiniam tobulejjimui: kartą per savaitę ši gydytoją rytinèse vizitacijose pakeisdavo vienas iš jo jaunesniujų kolegų, o tuo metu B. Lownas skaitydavo naujausią ir senesnę medicininę literatūrą. Kaip prisimena J. Alpert, po kiekvieno vizitacijos B. Lownas su kolegomis dalindavosi gausiomis literatūros žiniomis, susijusiomis su kiekvieno paciento būkle.

J. Alpert teigimu, B. Lownas buvo itin demesingas ir pagarbus visiems savo pacientams: „Gyd. B. Lownas gyde daug garsenybių, žmonès vizitui pas ji vykdavo iš viso pasaulio. Visiems pacientams gyd. B. Lownas skirdavo vienodai dèmesio ir gydydavo juos taip pat, kaip paprastus bostoniečius, gyvenančius ligoninès apylinkèse. Gydytojas nuolat pabrèždavo, kad kiekvienas pacientas yra individuali asmenybè, todèl su juo turètų būti elgiamasi kaip su savitus poreikius turinčiu ponu, o ne „63 metu pacientu, sergančiu miokardo infarktu“.

Likus vos keletui mènesių iki 100-ojo gimtadienio, B. Lownas 2021 vasario 16 d. mirè savo namuose, Masačiusetse (JAV) [6].

Bernardo Lowno atminimas lieka ịamžintas kasdienèje kardiologijos praktikoje, kurią gydytojas visiems laikams pakeitè savo pastabumu ir išradingumu. B. Lownas istorijoje išliks kaip inovatyvus bei drąsus visuomenès veikèjas, sukūręs svarų indèlį žmonių sveikatai ir gerovei visame pasaulyje. Pasak J. Alpert, „Jo įtaka išliks nepaisant mirties. Nèra geresnio idealaus kardiologo ir akademiko pavyzdžio, nei gydytojas Bernardas Lownas."

\section{Literatūra}

1. Dr. Bernard Lown. Lown Institute.

https://lowninstitute.org/about/dr-bernard-lown/
2. McFadden RD. Bernard Lown, inventive heart doctor and antiwar activist, dies at 99. The New York Times.

https:/www.nytimes.com/2021/02/16/health/bernard-lowndead.html

3. Bernard Lown • LITFL Medical Blog • Medical Eponym Library. Life in the Fast Lane. https://itfl.com/bernard-lown/

4. Langer E. Bernard Lown, physician who rallied doctors against nuclear war, dies at 99. Washington Post.

https://www.washingtonpost.com/local/obituaries/ bernard-lown-dead/2021/02/17/71 ce93fc-7121-11eb-85fae0ccb3660358_story.html

5. Joe Scott. Dr Bernard Lown Keynote. https://www.youtube.com/watch?v=zU6hyxBcY3s\&t= 1639s\&ab channel=LownInstitute

6. In memoriam: Bernard Lown, innovative cardiologist, antiwar activist. https://www.hsph.harvard.edu/news/features/in-memoriam-bernard-lown-innovative-cardiologist-antiwar-activist/

7. Levine SA, Lown B. "Armchair" treatment of acute coronary thrombosis. J Am Med Assoc. 1952;148(16):1365-9. https://doi.org/10.1001/jama.1952.02930160001001

8. Eisenberg M. The resuscitation greats. Bernard Lown and defibrillation. Resuscitation. 2006;69(2):171-3.

https://doi.org/10.1016/j.resuscitation.2006.01.004

9. The coronary artery entrapment. Dr. Bernard Lown's blog. https://bernardlown.wordpress.com/2012/07/31/the-coronaryartery-entrapment/

10. Nagourney E. Rene Favaloro, 77, a leader in early heartbypass surgery. The New York Times. https://www.nytimes. com/2000/08/01/world/rene-favaloro-77-a-leader-in-earlyheart-bypass-surgery.html

11. Lown B, Salzberg H, Enselberg CD, Weston RE. Interrelation between potassium metabolism and digitalis toxicity in heart failure. Proc Soc Exp Biol Med 1951;76(4):797-801. https://doi.org/10.3181/00379727-76-18636

12. Lown B. Lidocaine: antiarrhythmic panacea or cardiac cosmetic agent? JAMA 1981;246(21):2482-3. https://doi.org/10.1001/jama.246.21.2482

13. Lown B, Wolf M. Approaches to sudden death from coronary heart disease. Circulation. 1971 Jul 1;44(1):130-42. https://doi.org/10.1161/01.CIR.44.1.130

14. IPPNW: a brief history - international physicians for the prevention of nuclear war. https://www.ippnw.org/about/ippnwa-brief-history

15. Nicholls M. Evgeny Chazov and Bernard Lown. Eur Heart J 2019;40(28):2276-9. https://doi.org/10.1093/eurheartj/ehz468

16. ProCor: what is ProCor? https://web.archive.org/web/20140222033654/http://www. procor.org/about/about_show.htm?doc_id=693601

17. The lost art of healing. https:/www.goodreads.com/work/ 
best_book/177208-the-lost-art-of-healing-practicing-compassion-in-medicine

18. Prescription for survival. https:/www.goodreads.com/work/ best_book/2633167-prescription-for-survival-a-doctor-s-journey-to-end-nuclear-madness-bk

\section{DR. BERNARD LOWN: INVENTOR OF A MODERN DEFIBRILLATOR AND THE NOBEL PEACE PRIZE RECIPIENT OF LITHUANIAN ORIGIN}

A. Martinonytė, P. Šerpytis, J.S. Alpert, A. Laucevičius

Keywords: Bernard Lown, Boruchas Lacas, defibrillator, arrhythmias, Nobel Peace Prize.

Summary

The article covers the biography of Dr. Bernard Lown (1921 2021), a famous cardiologist of Lithuanian Jewish origin. It high- lights his notable achievements in medicine and social activism. Lown, born in Utena, has radically changed modern cardiology by inventing the direct current defibrillator and making important innovations in cardiac care. Dr. Lown is also remembered as a leader of the Nobel Peace Prize-winning initiative "International Physicians for the Prevention of Nuclear War" (IPPNW) and for his work towards better healthcare in developing countries. Dr. Bernard Lown is remembered as a prominent figure who dedicated his life to human beings and humanity.

Correspondence to: aurelija.martinonyte@gmail.com

Gauta 2021-04-27 